\title{
Camptothecin inhibits the progression of NPC by regulating TGF- $\beta$-induced activation of the PI3K/AKT signaling pathway
}

\author{
BEN-SHAN LI ${ }^{1,2}$, JI-YI HUANG ${ }^{3}$, JING GUAN $^{2}$ and LONG-HUA CHEN ${ }^{1}$ \\ ${ }^{1}$ Department of Radiation Oncology, Nanfang Hospital Southern Medical University, Guangzhou, Guangdong 510515; \\ Departments of ${ }^{2}$ Oncology and ${ }^{3}$ E.N.T., People's Hospital of Jiangmen, Jiangmen, Guangdong 529000, P.R. China
}

Received July 10, 2017; Accepted January 11, 2018

DOI: $10.3892 / \mathrm{ol} .2018 .8688$

\begin{abstract}
Nasopharyngeal carcinoma (NPC) is a type of cancer that is characterized by increased invasiveness, metastatic potential and tumor recurrence. Camptothecin has been demonstrated to exhibit anticancer activity. However, the potential underlying molecular mechanisms mediated by camptothecin in NPC cells remain elusive. In the present study, the efficacy of camptothecin for NPC was investigated in vitro and in vivo. Additionally, the potential signaling pathway mediated by camptothecin in NPC cells was also examined. The results indicated that the viability and aggressiveness of NPC cells were suppressed by camptothecin treatment in a dose-dependent manner. Camptothecin administration downregulated the expression levels of cell-cycle-associated proteins including cyclin 1, cyclin-dependent kinase (CDK)1 and CDK2 in NPC cells. Expression levels of migration-associated proteins including vimentin, fibronectin and epithelial cadherin were regulated by camptothecin treatment in NPC cells. Additionally, camptothecin inhibited the expression of transforming growth factor- $\beta$ (TGF- $\beta$ ), phosphoinositide 3-kinase (PI3K) and protein kinase B (AKT), whereas TGF- $\beta$ overexpression abrogated camptothecin-mediated inhibition of PI3K and AKT expression and camptothecin-mediated inhibition of the viability and aggressiveness of NPC cells. Camptothecin significantly inhibited tumor growth and increased survival times in a mouse model of cancer. In conclusion, these results indicate that camptothecin treatment may inhibit the viability of NPC cells and aggressiveness by regulating the TGF- $\beta$-induced PI3K/AKT signaling pathways, which in turn may be a potential molecular target for the treatment of NPC.
\end{abstract}

Correspondence to: Professor Long-Hua Chen, Department of Radiation Oncology, Nanfang Hospital Southern Medical University, 1838 North of Guangzhou Avenue, Baiyun, Guangzhou, Guangdong 510515, P.R. China

E-mail: chenlonghuasci@yeah.net

Key words: nasopharyngeal carcinoma, camptothecin, transforming growth factor- $\beta$, phosphoinositide 3-kinase/protein kinase B

\section{Introduction}

Nasopharyngeal carcinoma (NPC) is a type of cancer that occurs in the top and side of the nasopharyngeal cavity $(1,2)$. Clinical observation and experimental studies have indicated that pathogenic factors of NPC are extensive, including hereditary factors, viral infections and environmental factors $(3,4)$. A previous study has suggested that future perspectives for clinical research should include prospective and observational cohort studies, which may assess the effects of different risk factors in the development of NPC and the effectiveness of investigational treatments (5). Although previous studies have investigated numerous anticancer drugs including nimotuzumab, oxaliplatin and gemcitabine for the treatment of NPC (6-9), the therapeutic outcomes are not encouraging so far. Therefore, exploring efficient anticancer agents and the potential underlying molecular mechanisms of cellular migration and metastasis in NPC are required.

Camptothecin $\left(\mathrm{C}_{20} \mathrm{H}_{16} \mathrm{~N}_{2} \mathrm{O}_{4}\right)$ is an anticancer drug that exhibits high efficacy for the treatment of gastrointestinal, and head and neck cancer $(10,11)$. Clinical pathologists have widely investigated the effects of camptothecin in the treatment of human cancer cells $(12,13)$. A previous study demonstrated that camptothecin may induce human colon cancer cell death via the downregulation of mitogen-activated protein kinase phosphatase-1 and sustaining extracellular-signal-regulated kinase 1/2 activation (14). Additionally, Sun et al (15) have demonstrated that camptothecin may inhibit the growth and invasion of prostate cancer cells via phosphoinositide 3-kinase (PI3K)/protein kinase B (AKT), $\alpha v \beta 3 / \alpha v \beta 5$ and matrix metalloproteinase (MMP)-2/-9 signaling pathways. Furthermore, a pharmacodynamic and pharmacogenomic study revealed that a nanoparticle conjugate of camptothecin, CRLX101, is efficient for the treatment of cancer (16). Although previous studies have indicated the efficacy of camptothecin in solid tumors $(17,18)$, only a limited number of studies have investigated the function of camptothecin in NPC cells. To the best of our knowledge, no study has elucidated the potential molecular mechanism mediated by camptothecin in the progression of NPC.

In the present study, the inhibitory effects of camptothecin on the viability and aggressiveness of NPC cells were assessed. Potential molecular mechanisms mediated by camptothecin in NPC cells were also examined. The results of the present 
study demonstrated that camptothecin administration significantly inhibited the viability and aggressiveness of NPC cells by regulating transforming growth factor- $\beta$ (TGF- $\beta$ )-induced activation of the PI3K/AKT signaling pathway, and thus it may be a potential anticancer agent for NPC therapy.

\section{Materials and methods}

Ethics statement. The present study was performed in strict accordance with the recommendations of the Guide for the Care and Use of Laboratory Animals (19). All experimental protocols were approved by the Ethics Committee of Nanfang Hospital of Southern Medical University (Guangzhou, China).

Cells and reagents. NPC cell lines HK1 and C666-1 were a gift from Professor Jia-Huan Han (Department of Microbiology, Xiamen University). All tumor cells were cultured in Dulbecco's modified Eagle's medium (Sigma-Aldrich; Gibco; Thermo Fisher Scientific, Inc., Waltham, MA, USA) supplemented with $10 \%$ fetal bovine serum (Invitrogen; Thermo Fisher Scientific, Inc.). All cells were cultured at $37^{\circ} \mathrm{C}$ in a humidified atmosphere containing $5 \% \mathrm{CO}_{2}$.

Endogenous overexpression of TGF- $\beta$. HK1 and C666-1 cells were cultured to $85 \%$ confluence. Cells $\left(1 \times 10^{7}\right)$ were then transfected with pedue12.4-TGF- $\beta$ (pTGF- $\beta$; $100 \mathrm{pmol}$ ) or empty vector plasmid (control; $100 \mathrm{pmol}$ ) using Lipofectamine ${ }^{\circledR} 2000$ (all Invitrogen; Thermo Fisher Scientific, Inc.). Stable TGF- $\beta$-overexpressing HK1 and C666-1 cells were selected using a glutamine synthetase screening system (20). Cells were used for further analysis after $72 \mathrm{~h}$ transfection. TGF- $\beta$-overexpressing HK1 and C666-1 were treated with $6 \mu \mathrm{M}$ camptothecin (pTGF- $\beta$-CA) for $24 \mathrm{~h}$ at $37^{\circ} \mathrm{C}$.

MTT assays. HK1 and C666-1 were transfected with control or pTGF- $\beta$ and cultured in a 96-well plate for $48 \mathrm{~h}$ at $37^{\circ} \mathrm{C}$. HK1 and C666-1 cells were treated with 2, 6 or $10 \mu \mathrm{M}$ camptothecin and incubated at $37^{\circ} \mathrm{C}$ for 24,48 and $72 \mathrm{~h}$. After incubation, $20 \mu \mathrm{l}$ MTT $(5 \mathrm{mg} / \mathrm{ml})$ solution was added to each well and the plate was further incubated for $4 \mathrm{~h}$. Medium was removed and $100 \mu \mathrm{l}$ dimethylsulfoxide was added to the wells to solubilize the crystals. Cell viability was determined by measuring the absorbance at $450 \mathrm{~nm}$ using a plate reader (Bio-Rad Laboratories, Inc., Hercules, CA, USA).

Cell invasion and migration assays. Stable TGF- $\beta$-overexpressing HK1 and C666-1 cells were cultured with camptothecin $(2 \mu \mathrm{M})$ or PBS (control) at $37^{\circ} \mathrm{C}$ for $48 \mathrm{~h}$. Migration and invasion assays were performed in a 6-well culture plate with chamber inserts (BD Biosciences, Franklin Lakes, NJ, USA). For migration assays, HK1 and C666-1 cells $\left(1 \times 10^{4}\right.$ cells/well) were placed into the upper chamber $(8 \mu \mathrm{m}$ pores) and cultured for $48 \mathrm{~h}$ at $37^{\circ} \mathrm{C}$. For invasion assays, HK1 and C666-1 cells ( $1 \times 10^{4}$ cells well) were placed into the upper chamber with the Matrigel-coated membrane for $48 \mathrm{~h}$ at $37^{\circ} \mathrm{C}$. Migrating or invading $\mathrm{HK} 1$ and $\mathrm{C} 666-1$ cells were stained with $1 \%$ crystal violet for $30 \mathrm{~min}$ at $37^{\circ} \mathrm{C}$ and counted in at least three randomly selected fields using a light microscope (Nikon E400; Nikon Corp., Tokyo, Japan).
Analysis of cell cycle by flow cytometry. Flow cytometric analysis was performed to analyze the effects of camptothecin (6 $\mu \mathrm{M})$ on the cell cycle stages of HK1 and C666-1 cells. Exponentially grown HK1 and C666-1 cells or TGF- $\beta$-overexpressing HK1 and C666- 1 cells were treated with camptothecin $(6 \mu \mathrm{M})$ for $48 \mathrm{~h}$. Cells were washed, trypsinized and rinsed with PBS. All cells were fixed in $75 \%$ ice-cold ethanol for $5 \mathrm{~min}$ and then washed with PBS three times. The fixed cells were washed with RNase A $(20 \mu \mathrm{g} / \mathrm{ml}$; Fermentas; Thermo Fisher Scientific, Inc.) and stained with propidium iodide $(20 \mu \mathrm{g} / \mathrm{ml}$, Sigma-Aldrich; Merck KGaA, Darmstadt, Germany) for $10 \mathrm{~min}$ at $37^{\circ} \mathrm{C}$. The percentages of cells at S-phase were determined using a FACSCalibur instrument (BD Biosciences) and analyzed using BD FACSDiva ${ }^{\mathrm{TM}}$ Software (version 1.2; BD Biosciences).

Western blot analysis. Following treatment of HK1 and C666-1 cells with camptothecin $(6 \mu \mathrm{M})$ for $24 \mathrm{~h}$ at $37^{\circ} \mathrm{C}$, cells were harvested by scraping and lysed in radioimmunoprecipitation assay buffer (Sigma-Aldrich; Merck KGaA) followed by homogenization at $4^{\circ} \mathrm{C}$ for $10 \mathrm{~min}$. Protein concentration was measured by a bicinchoninic acid protein assay kit (Thermo Fisher Scientific, Inc.). Proteins $(10 \mu \mathrm{g})$ were separated by SDS-PAGE (12\% gels). The proteins were transferred onto membranes and blocked with 2\% BSA (Sigma-Aldrich; Merck KGaA). Membranes were incubated with rabbit anti-human cyclin 1 (1:500; ab152116), anti-cyclin-dependent kinase 1 (CDK1; 1:500; ab18), anti-cyclin-dependent kinase 2 (CDK2; 1:500; ab32147), TGF- $\beta$ (1:500; ab92486), anti-PI3K (1:500; ab86714), anti-phosphorylated PI3K (pPI3K; 1:500; ab138364), anti-AKT (1:500; ab64148), anti-phosphorylated AKT (pAKT; 1:500; ab38449) anti-vimentin (1:500; ab92547), anti-fibronectin (1:500; ab2413), anti-E-cadherin (1:500; ab11512) or anti- $\beta$-actin (1:500; ab32572; all Abcam, Cambridge, UK) antibody for $12 \mathrm{~h}$ at $4^{\circ} \mathrm{C}$. Goat anti-rabbit horseradish peroxidase-conjugated secondary antibody (cat no. 6726; Bio-Rad Laboratories, Inc.) was used at 1:5,000 dilution for $2 \mathrm{~h}$ at $37^{\circ} \mathrm{C}$ and immunoreactive protein bands were detected using a western blotting luminol reagent. The results were visualized using a chemiluminescence detection system (GE Healthcare, Chicago, IL, USA).

Animal study. Pathogen-free male Balb/c (8-weeks old; body weight, 25-32 g) mice were purchased from Slack Laboratory Animal Co., Ltd. (Shanghai, China). Mice were maintained on a $12 \mathrm{~h}$ light/12 h dark cycle with free access to diet and water. Experimental mice were implanted with HK1 cells ( $1 \times 10^{8}$ cells) into the groin and were divided into two groups (20 mice/group). Treatment was initiated on day 3 following tumor implantation (diameter, 5-6 mm). Tumor-bearing mice were intravenously injected with camptothecin $(10 \mathrm{mg} / \mathrm{kg})$ or PBS (control) once daily for 9 days. The tumor volumes were calculated according to a previous study (21). Mice were sacrificed when the tumor diameter reached $18 \mathrm{~mm}$ in each group.

Immunohistochemical staining. Xenograft mouse tumor tissue was fixed in $10 \%$ formaldehyde for $2 \mathrm{~h}$ at $37^{\circ} \mathrm{C}$ and embedded in paraffin. Paraffin-embedded tissue samples were cut into serial sections of $4-\mu \mathrm{m}$ thickness. Antigen retrieval was also performed on tumor sections. Tumor sections were 

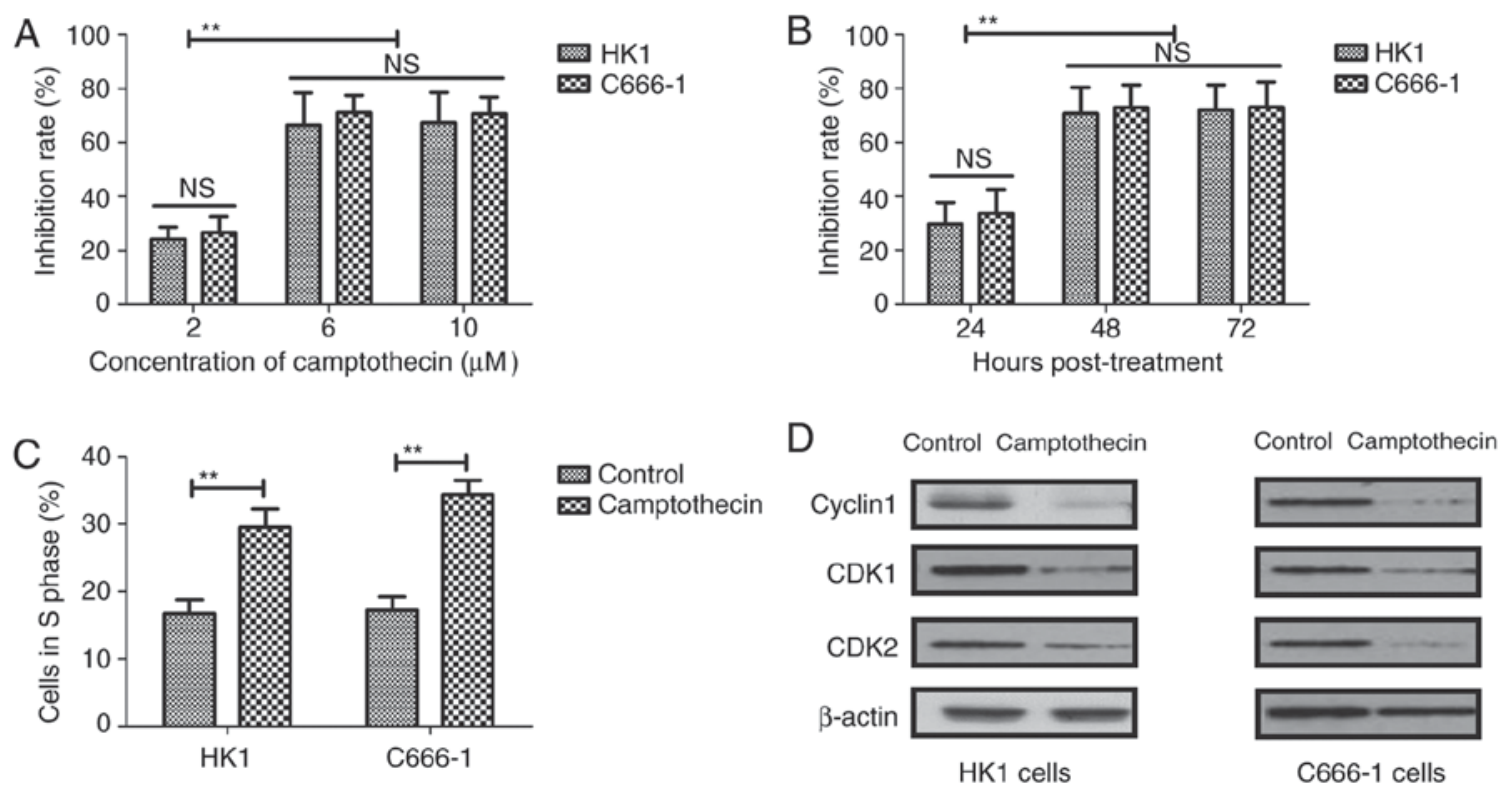

Figure 1. Camptothecin suppresses cellular viability and induces cell cycle arrest in NPC cells. (A) An MTT assay revealed that camptothecin inhibits the viability of HK1 and C666-1 cells in a dose-dependent (2, 6 and $10 \mu \mathrm{M})$ manner. (B) Camptothecin inhibits the viability of HK1 and C666-1 cells in a time-dependent (24, 48 and $72 \mathrm{~h})$ manner as assessed using an MTT assay. (C) Flow cytometric analysis of the cell cycle demonstrated that camptothecin $(6 \mu \mathrm{M})$ induces cell cycle arrest at S-phase in HK1 and C666-1 cells. (D) Western blot analysis indicated that camptothecin $(6 \mu \mathrm{M})$ downregulates the expression of cell-cycle-associated proteins, cyclin 1, CDK1 and CDK2 in NPC cells. $\beta$-actin was used as a loading control. "*P<0.01. NPC, nasopharyngeal carcinoma; NS, not significant; CDK, cyclin-dependent kinase.

blocked with $5 \% \mathrm{BSA}$ for $2 \mathrm{~h}$ at $37^{\circ} \mathrm{C}$ and then incubated with rabbit anti-human TGF- $\beta$ (1:500; ab92486), anti-PI3K (1:500; ab86714) and anti-AKT (1:500; ab64148; all Abcam) antibodies for $24 \mathrm{~h}$ at $4^{\circ} \mathrm{C}$. Tumor tissues were washed with PBS three times and incubated with goat anti-rabbit horseradish peroxidase-conjugated anti-rabbit $\mathrm{IgG}$ antibodies (cat. no. 6726; Bio-Rad Laboratories, Inc.) for $24 \mathrm{~h}$ at $4^{\circ} \mathrm{C}$. The slides were observed using a chemiluminescence detection system (Version 3.0; Sigma-Aldrich, Merck KGaA). Images were captured with an Olympus fluorescence microscope (Olympus Corporation, Tokyo, Japan).

Statistical analysis. Data were analyzed using SPSS software (version 19.0; IBM Corp., Armonk, NY, USA) and GraphPad Prism (version 5; GraphPad Software, Inc., La Jolla, CA, USA). Data are expressed as the mean \pm standard error of the mean. Results were analyzed by Student's t-test or one-way analysis of variance followed by Tukey's honestly significant difference test. All experiments were performed at least three times. $\mathrm{P}<0.05$ was considered to indicate a statistically significant difference.

\section{Results}

Camptothecin treatment suppresses viability and induces cell cycle arrest in NPC cells. Fig. 1A indicates that camptothecin treatment $(2,6$ or $10 \mu \mathrm{M})$ inhibited the viability of HK1 and C666-1 cells in a dose-dependent manner after $24 \mathrm{~h}$ incubation. Results indicated that $6 \mu \mathrm{M}$ had the same inhibitory rate the viability for HK1 and C666-1 cells. Additionally, NPC cells treated with $6 \mu \mathrm{M}$ camptothecin displayed maximal inhibition of viability. HK1 and C666-1 cells were treated with camptothecin $(6 \mu \mathrm{M})$ for 24,48 and $72 \mathrm{~h}$. The results indicated that camptothecin treatment significantly inhibited the viability of HK1 and C666-1 cells in a time-dependent manner (Fig. 1B). The data identified no differences between the 48 and 72 h incubation. Next, flow cytometric analysis of the cell cycle was performed to determine whether camptothecin $(6 \mu \mathrm{M})$ treatment induces cell cycle arrest in HK1 and C666-1 cells after $48 \mathrm{~h}$ incubation. The results indicated that camptothecin treatment induced cell cycle arrest at S-phase in HK1 and C666-1 cells (Fig. 1C). Western blot analysis indicated that camptothecin downregulated the expression of cell-cycle-associated proteins, including cyclin 1, CDK1 and CDK2, in HK1 and C666-1 cells (Fig. 1D). These results indicate that camptothecin treatment may suppress cellular viability and induce cell cycle arrest in NPC cells.

Camptothecin treatment inhibits the migration and invasion of NPC cells. The effects of camptothecin on tumor aggressiveness were analyzed using migration and invasion assays. The results indicated that camptothecin treatment $(6 \mu \mathrm{M})$ significantly inhibited migration and invasion of NPC cells after $48 \mathrm{~h}$ of incubation ( $\mathrm{P}<0.01$; Fig. $2 \mathrm{~A}$ and $\mathrm{B}$ ). Additionally, western blot analysis revealed that camptothecin treatment $(6 \mu \mathrm{M})$ downregulated vimentin and fibronectin expression and upregulated E-cadherin expression levels in NPC cells (Fig. 2C). These results indicate that camptothecin treatment may inhibit migration and invasion by regulating the expression of migration-associated proteins, including vimentin, fibronectin and E-cadherin, in NPC cells.

Camptothecin regulates the viability of NPC cells via the TGF- $\beta$-induced PI3K/AKT signaling pathway. Potential molecular mechanisms involved in camptothecin-mediated 

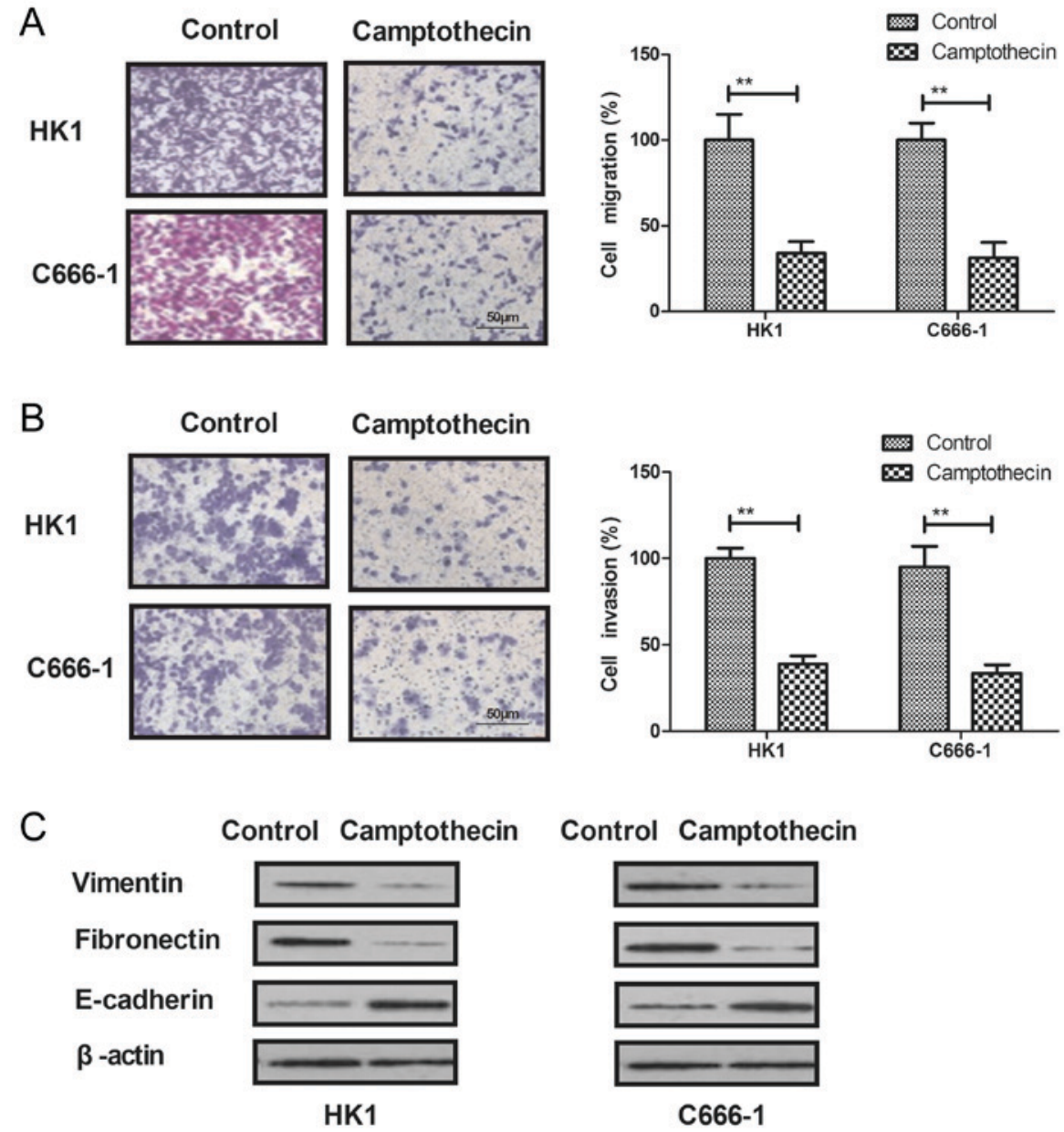

Figure 2. Camptothecin treatment inhibits migration and invasion of NPC cells. (A) At $48 \mathrm{~h}$ post-treatment, camptothecin $(6 \mu \mathrm{M})$ significantly inhibits migration (B) and invasion of NPC cells. Scale bar, $50 \mu \mathrm{m}$. ${ }^{* *} \mathrm{P}<0.01$. (C) Western blot analysis revealed that camptothecin $(6 \mu \mathrm{M})$ treatment downregulates the expression of vimentin and fibronectin, and upregulates the expression of E-cadherin in NPC cells. $\beta$-actin was used as a loading control. NPC, nasopharyngeal carcinoma.

viability of NPC cells were investigated. Western blot analysis revealed that camptothecin treatment $(6 \mu \mathrm{M})$ inhibited the expression levels of TGF- $\beta$, PI3K, AKT, pPI3K and pAKT in NPC cells (Fig. 3A). Additionally, the effects of TGF- $\beta$ overexpression in camptothecin-mediated regulation of tumor development was assessed by transfecting the cells with pTGF- $\beta$-CA. Western blot analysis revealed that endogenous TGF- $\beta$ overexpression abrogated camptothecin-mediated inhibition of PI3K and AKT expression (Fig. 3B). The results indicated that TGF- $\beta$ overexpression abolished camptothecin-mediated inhibition of viability, migration and invasion of NPC cells (Fig. 3C-E). These results indicate that camptothecin regulates the viability of NPC cells by regulating TGF- $\beta$-induced activation of the PI3K/AKT signaling pathway.

Camptothecin treatment inhibits tumor growth and increases survival times in vivo. Anticancer efficacy of camptothecin was also determined in vivo in tumor-bearing mice. Camptothecin treatment significantly inhibited tumor growth compared with the control group (Fig. 4A). Camptothecin significantly inhibited TGF- $\beta, \mathrm{PI} 3 \mathrm{~K}$ and AKT expression in tumor sections as assessed by immunohistochemistry (Fig. 4B). Additionally, camptothecin significantly increased the survival time of mice (120 days) (Fig. 4C). These results indicate that camptothecin treatment may inhibit tumor growth and increase the survival time of tumor-bearing mice.

\section{Discussion}

Currently, a number of strategies that target the migration and invasion of NPC cells have been proposed for the therapy of NPC $(2,8)$. In the present study, a camptothecin-mediated signaling pathway in NPC cells was investigated. The results indicated that $6 \mu \mathrm{M}$ camptothecin exhibited maximal toxicity towards NPC cells. Previous studies have revealed that NPC occurs in the epithelial lining of the nasopharynx and patients with NPC develop regional lymph node metastasis and distant metastasis $(22,23)$. The results of the present study demonstrated that camptothecin treatment significantly inhibited the viability and aggressiveness of NPC cells and also suppressed tumor growth in tumor-bearing mice. Previous studies suggest that camptothecin is an efficient anticancer drug for the treatment of various types of cancer $(24,25)$. Notably, the results of the present study indicated that camptothecin regulated the viability of NPC cells by regulating TGF- $\beta$-induced activation of the PI3K/AKT signaling pathway. 

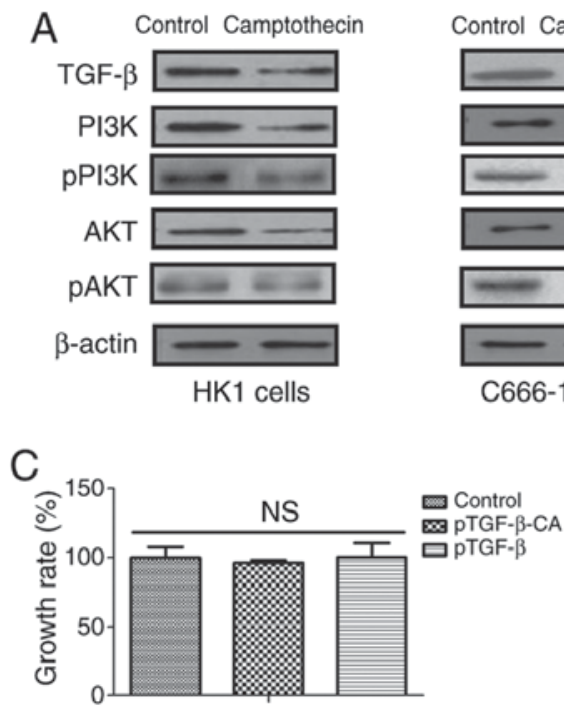

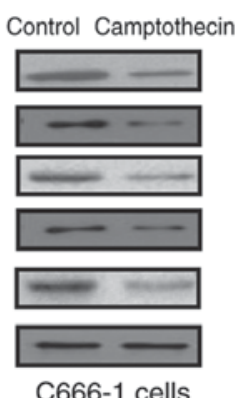

$\mathrm{D}$

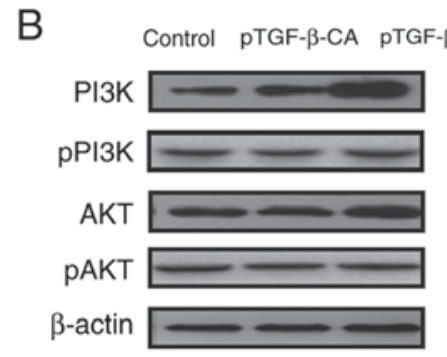

HK1 cells

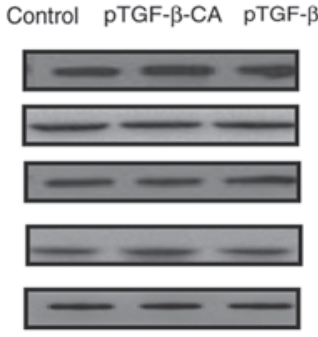

C666-1 cells

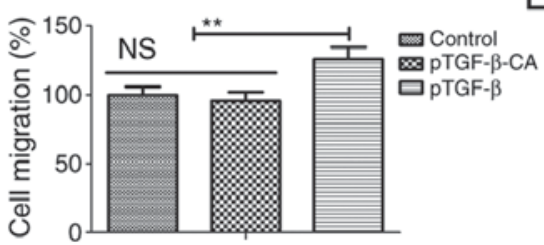

$\mathrm{E}$

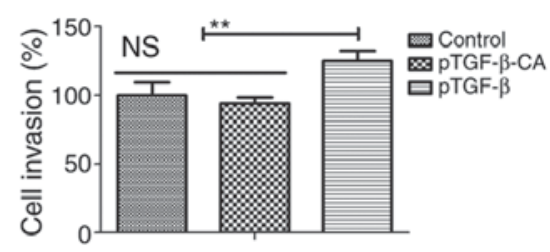

Figure 3. Camptothecin regulates the viability of NPC cells by regulating TGF- $\beta$-induced activation of the PI3K/AKT signaling pathway. (A) Western blot analysis revealed that camptothecin $(6 \mu \mathrm{M})$ treatment inhibits the expression of TGF- $\beta$, PI3K and AKT in NPC cells. (B) Western blot analysis demonstrated that TGF- $\beta$ overexpression abrogates camptothecin-mediated inhibition of PI3K, pPI3K pAKT and AKT expression in NPC cells. (C) An MTT assay revealed that TGF- $\beta$ overexpression abolishes camptothecin-mediated inhibition of viability of NPC cells. (D) TGF- $\beta$ overexpression abrogates camptothecin-mediated inhibition of migration (E) and invasion of NPC cells. $\beta$-actin was used as a loading control. ${ }^{* *} \mathrm{P}<0.01$. NPC, nasopharyngeal carcinoma; TGF- $\beta$, transforming growth factor- $\beta$; PI3K, phosphoinositide 3-kinase; AKT, protein kinase B; pPI3K, phosphorylated PI3K; pAKT, phosphorylated AKT; NS, not significant.
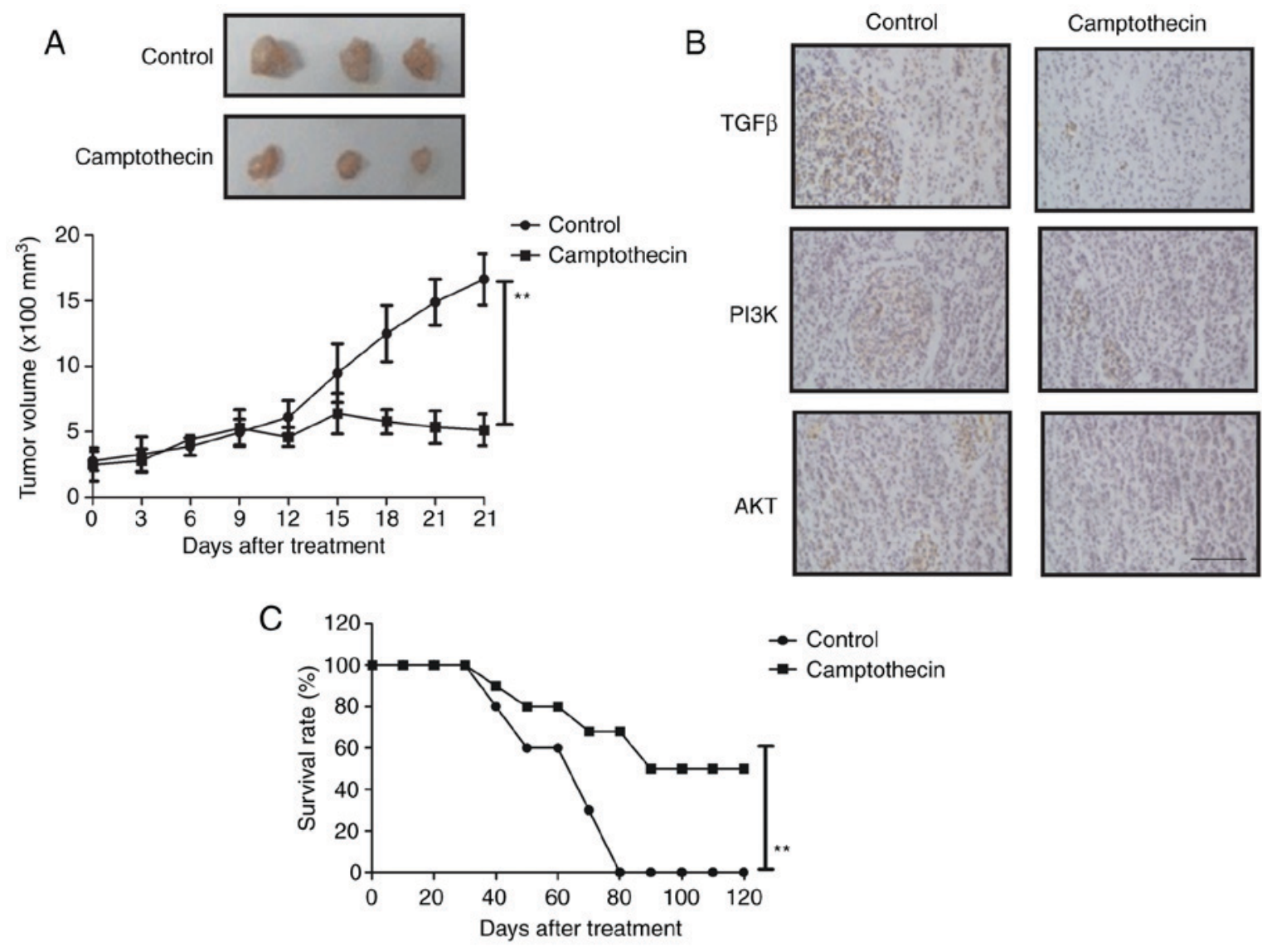

Figure 4. Camptothecin treatment inhibits tumor growth and increases survival times in vivo. (A) Camptothecin treatment (10 mg/kg) inhibited tumor growth in tumor-bearing mice compared with the control group. (B) Camptothecin treatment (10 mg/kg) decreased TGF- $\beta$, PI3K and AKT expression in tumor sections as assessed by immunohistochemistry. (C) Camptothecin treatment increased the survival times of mice during the 120-day treatment. Scale bars, $20 \mu \mathrm{m} .{ }^{* *} \mathrm{P}<0.01$. TGF- $\beta$, transforming growth factor- $\beta$; PI3K, phosphoinositide 3-kinase; AKT, protein kinase B.

Increased incidence of NPC and increased mortality rates for patients with NPC have been reported in China (26-28).
The results of the present study indicated that camptothecin treatment significantly inhibited cellular migration and 
invasion via regulating the expression levels of vimentin, fibronectin and E-cadherin in NPC cells. Camptothecin synergizes with cyclin-dependent kinase inhibitors, and regulates the viability and aggressiveness of small cell lung cancer cells (29). Mollica et al (30) suggested that camptothecin treatment led to benefits in patients with colorectal cancer. The results of the present study demonstrated that camptothecin treatment induced cell cycle arrest at S-phase via downregulating the expression levels of cyclin, CDK1 and CDK2 in NPC cells.

In the present study, the potential molecular mechanisms involved in camptothecin-mediated regulation of NPC development were investigated. A previous study reported that camptothecin and 10-hydroxycamptothecin inhibited the viability and metastasis of lung cancer cells via p38 mitogen-activated protein kinase, extracellular-signal-regulated kinase and AKT signaling pathways (31). Additionally, camptothecin suppressed platelet-derived growth factor-BB-induced proliferation of rat aortic vascular smooth muscle cells through the inhibition of the PI3K/AKT signaling pathway (32). The results of the present study indicated that camptothecin treatment inhibited TGF- $\beta$, PI3K and AKT expression in NPC cells, whereas TGF- $\beta$ overexpression abrogated camptothecin-mediated inhibition of PI3K and AKT expression. Additionally, it has been reported that camptothecin suppressed MMP-9 and vascular endothelial growth factor expression in DU145 cells through PI3K/AKT-mediated inhibition of nuclear factor $-\kappa \mathrm{B}$ activity and nuclear factor erythroid 2-related factor 2-dependent induction of heme oxygenase-1 expression (33). The results of the present study demonstrated that camptothecin regulated the viability of NPC cells through TGF- $\beta$-induced activation of the PI3K/AKT signaling pathway, which led to longer survival for tumor-bearing mice.

In conclusion, a number of studies have demonstrated the anticancer efficacy of camptothecin in preclinical settings, which may contribute to the treatment of NPC. The results of the present study indicated the underlying molecular mechanism by which camptothecin may suppress the viability and aggressiveness of NPC and regulate TGF- $\beta$-induced activation of the PI3K/AKT signaling pathway.

\section{Acknowledgements}

Not applicable.

\section{Funding}

No funding was received.

\section{Availability of data and materials}

The datasets used and/or analyzed during the current study are available from the corresponding author on reasonable request.

\section{Authors' contributions}

BSL and JYH performed all experiments. JG analyzed experimental data in this study. LHC designed all experiments in the present study.

\section{Ethics approval and consent to participate}

The present study was approved by the Ethics Committee of Nanfang Hospital of Southern Medical University (Guangzhou, China).

\section{Consent for publication}

Not applicable.

\section{Competing interests}

The authors declare that they have no competing interests.

\section{References}

1. Fan W and Du J: Nasal polyps associated with nasopharyngeal carcinoma in child: One case report and review. Lin Chung Er Bi Yan Hou Tou Jing Wai Ke Za Zhi 27: 273-274, 2013 (In Chinese)

2. Colaco RJ, Betts G, Donne A, Swindell R, Yap BK, Sykes AJ, Slevin NJ, Homer JJ and Lee LW: Nasopharyngeal carcinoma: A retrospective review of demographics, treatment and patient outcome in a single centre. Clin Oncol (R Coll Radiol) 25: 171-177, 2013.

3. Tsang CM and Tsao SW: The role of Epstein-Barr virus infection in the pathogenesis of nasopharyngeal carcinoma. Virol Sin 30: 107-121, 2015.

4. Dawson CW, Port RJ and Young LS: The role of the EBV-encoded latent membrane proteins LMP1 and LMP2 in the pathogenesis of nasopharyngeal carcinoma (NPC). Semin Cancer Biol 22: 144-153, 2012.

5. Strazzulla A, Barreca GS, Giancotti A, Pisani V, Costa C, Zicca E, La Boria A, Roveda L, Liberto MC, Tucci L, et al: Nasopharyngeal carcinoma: Review of the literature with a focus on therapeutical implications. Infez Med 23: 224-229, 2015.

6. Gioacchini FM, Tulli M, Kaleci S, Magliulo G and Re M: Prognostic aspects in the treatment of juvenile nasopharyngeal carcinoma: A systematic review. Eur Arch Otorhinolaryngol 274: 1205-1214, 2017.

7. Xiao W, He Z, Xing C, Zhen W, Wang $\mathrm{S}$ and Lin $\mathrm{H}$ : Clinicopathologic features and treatment of breast metastasis from nasopharyngeal carcinoma: A report of two cases and literature review. Oncol Lett 10: 3675-3681, 2015.

8. Setton J, Wolden S, Caria N and Lee N: Definitive treatment of metastatic nasopharyngeal carcinoma: Report of 5 cases with review of literature. Head Neck 34: 753-757, 2012.

9. Caponigro F, Longo F, Ionna F and Perri F: Treatment approaches to nasopharyngeal carcinoma: A review. Anticancer Drugs 21: 471-477, 2010

10. Yeo CD, Lee SH, Kim JS, Kim SJ, Kim SC, Kim YK, Kang HH, Yoon HK, Song JS and Moon HS, et al: A multicenter phase II study of belotecan, a new camptothecin analogue, in elderly patients with previously untreated, extensive-stage small cell lung cancer. Cancer Chemother Pharmacol 72: 809-814, 2013.

11. Arakawa Y, Ozaki K, Okawa Y and Yamada H: Three missense mutations of DNA topoisomerase I in highly camptothecin-resistant colon cancer cell sublines. Oncol Rep 30: 1053-1058, 2013.

12. Bertozzi D, Marinello J, Manzo SG, Fornari F, Gramantieri L and Capranico G: The natural inhibitor of DNA topoisomerase I, camptothecin, modulates HIF- $1 \alpha$ activity by changing miR expression patterns in human cancer cells. Mol Cancer Ther 13: 239-248, 2014.

13. Veloso A, Biewen B, Paulsen MT, Berg N, Carmo de Andrade Lima L, Prasad J, Bedi K, Magnuson B, Wilson TE and Ljungman M: Genome-wide transcriptional effects of the anti-cancer agent camptothecin. PLoS One 8: e78190, 2013.

14. Lee M, Young Kim S, Kim J, Kim HS, Kim SM and Kim EJ: Mitogen-activated protein kinase phosphatase-1 inhibition and sustained extracellular signal-regulated kinase $1 / 2$ activation in camptothecin-induced human colon cancer cell death. Cancer Biol Ther 14: 1007-1015, 2013. 
15. Sun LC, Luo J, Mackey LV, Fuselier JA and Coy DH: A conjugate of camptothecin and a somatostatin analog against prostate cancer cell invasion via a possible signaling pathway involving PI3K/Akt, alphaVbeta3/alphaVbeta5 and MMP-2/-9. Cancer Lett 246: 157-166, 2007.

16. Gaur S, Wang Y, Kretzner L, Chen L, Yen T, Wu X, Yuan YC, Davis $\mathrm{M}$ and Yen Y: Pharmacodynamic and pharmacogenomic study of the nanoparticle conjugate of camptothecin CRLX101 for the treatment of cancer. Nanomedicin 10: 1477-1486, 2014.

17. Tang Q, Ji F, Guo J, Wang J, Li Y and Bao Y: Directional modification of chrysin for exerting apoptosis and enhancing significantly anti-cancer effects of 10-hydroxy camptothecin. Biomed Pharmacother 82: 693-703, 2016.

18. Su H, Zhang P, Cheetham AG, Koo JM, Lin R, Masood A, Schiapparelli P, Quiñones-Hinojosa A and Cui H: Supramolecular crafting of self-assembling camptothecin prodrugs with enhanced efficacy against primary cancer cells. Theranostics 6 : 1065-1074, 2016.

19. Artyukhin AA: Plastic repair of the deferent duct with a silicone tubular prosthesis under conditions of a chronic experiment on laboratory animals. Bull Exp Biol Med 144: 91-95, 2007 (In English, Russian).

20. Renshaw A and Elsheikh TM: A validation study of the Focalpoint GS imaging system for gynecologic cytology screening. Cancer Cytopathol 121: 737-738, 2013.

21. Bai FL, Yu YH, Tian H, Ren GP, Wang H, Zhou B, Han XH, Yu QZ and Li DS: Genetically engineered Newcastle disease virus expressing interleukin-2 and TNF-related apoptosis-inducing ligand for cancer therapy. Cancer Biol Ther 15: 1226-1238, 2014

22. Turki S, Mardassi A, Abouda M, Hachicha A and Ben Jallel W: Orbital metastasis revealing an undifferenciated Carcinoma of nasopharyngeal type: A case report. Tunis Med 94: 148-151, 2016.

23. Genova P, Brunetti F, Bequignon E, Landi F, Lizzi V, Esposito F, Charpy C, Calderaro J, Azoulay D and de'Angelis N: Solitary splenic metastasis from nasopharyngeal carcinoma: A case report and systematic review of the literature. World J Surg Oncol 14: 184, 2016

24. Ding X, Matsuo K, Xu L, Yang J and Zheng L: Optimized combinations of bortezomib, camptothecin, and doxorubicin show increased efficacy and reduced toxicity in treating ora cancer. Anticancer Drugs 26: 547-554, 2015.
25. Chazin Ede L, Reis Rda R, Junior WT, Moor LF and Vasconcelos TR: An overview on the development of new potentially active camptothecin analogs against cancer. Mini Rev Med Chem 14: 953-962, 2014.

26. Zhang LF, Li YH, Xie SH, Ling W, Chen SH, Liu Q, Huang QH and Cao SM: Incidence trend of nasopharyngeal carcinoma from 1987 to 2011 in Sihui County, Guangdong Province, South China: An age-period-cohort analysis. Chin J Cancer 34: 350-357, 2015.

27. Liu S, Wang X, Shu J, Zhao Z, Sun Z and Luo B: Sequence analysis of EBV immune evasion gene BNLF2a in EBV associated tumors and healthy individuals from nasopharyngeal carcinoma endemic and non-endemic regions of China. J Med Virol 87: 1946-1952, 2015.

28. Tian W, Zhu FM, Wang WY, Cai JH, Zhang W, Li LX, Liu KL, Jin HK and Wang F: Sequence-based typing of HLA-A gene in 930 patients with nasopharyngeal carcinoma in Hunan province, southern China. Tissue Antigens 86: 15-20, 2015.

29. Hamilton G, Klameth L, Rath B and Thalhammer T: Synergism of cyclin-dependent kinase inhibitors with camptothecin derivatives in small cell lung cancer cell lines. Molecules 19: 2077-2088, 2014

30. Mollica A, Stefanucci A, Feliciani F, Cacciatore I, Cornacchia C and Pinnen F: Delivery methods of camptothecin and its hydrosoluble analogue irinotecan for treatment of colorectal cancer. Curr Drug Deliv 9: 122-131, 2012.

31. Liu Z, Zheng Q, Chen W, Wu M, Pan G, Yang K, Li X, Man S, Teng Y, Yu P and Gao W: Chemosensitizing effect of Paris Saponin I on Camptothecin and 10-hydroxycamptothecin in lung cancer cells via p38 MAPK, ERK, and Akt signaling pathways. Eur J Med Chem 125: 760-769, 2017.

32. Park ES, Kang SI, Yoo KD, Lee MY, Yoo HS, Hong JT, Shin HS, Kim B and Yun YP: Camptothecin inhibits platelet-derived growth factor-BB-induced proliferation of rat aortic vascular smooth muscle cells through inhibition of PI3K/Akt signaling pathway. Exp Cell Res 319: 982-991, 2013.

33. Jayasooriya RG, Park SR, Choi YH, Hyun JW, Chang WY and Kim GY: Camptothecin suppresses expression of matrix metalloproteinase-9 and vascular endothelial growth factor in DU145 cells through PI3K/Akt-mediated inhibition of NF- $\kappa \mathrm{B}$ activity and Nrf2-dependent induction of HO-1 expression. Environ Toxicol Pharmacol 39: 1189-1198, 2015. 